\title{
David Oliver: What you don't learn at medical school
}

\author{
David Oliver consultant in geriatrics and acute general medicine, Berkshire
}

Memories of my first weeks as a doctor remain vivid-elation at finally using six years' training, exhaustion from the nights, nervousness at unfamiliar situations, and new, bluffed attempts to project and inspire confidence.

Yes, it's August again, when new UK medical graduates hit the hospitals for their first paid jobs. My first year gave me fulfilled vocation, brutal hours, gallows humour, camaraderie, and two signed A4 sheets to submit for full General Medical Council registration.

Then I started my senior house officer job, aged 24, to do a week of 13 hour night shifts as the sole doctor in Manchester Royal's emergency department. I didn't meet a senior for two weeks; that was the way of things in 1990. I saw cases for which I was totally unprepared. I had to learn quickly. We should never return to those days: "See one; do one; teach one," is no route to patient safety.

This August is my 18th as a consultant supervising the new intake. The new doctors seem as good as those of my generation, with dedication just as strong. Today they're less thrown in at the deep end. More structured supervision helps to protect patients and practitioners and to guide career, as does shadowing doctors before starting. On-call work is still pressurised, but the hours are less ludicrous.

The transition from student hasn't changed that much, however. Medicine will always be a job learnt on the job. No amount of training in history, examination, investigation, and treatment can teach people skills, resilience, and "wardcraft." This includes time management, prioritisation, record keeping, knowing how to get things done, and dealing with those "what next" questions. How can I help patients who can't swallow their tablets? What warfarin dose? Whose job is the social services referral? What's a red flag? And when is it safe to watch and wait?

People skills primarily concern patients and their families. Medical students get plenty of training in speaking to patients about their conditions, how this affects their lives, and their treatment. But they learn less about complex family dynamics, public beliefs, and expectations about what services can deliver. How is it best to approach people who are unhappy, angry, or uncommunicative? Your colleagues will also test your people skills, including those who are workshy, unsupportive, demanding, or hard to get on with.

Resilience matters. How do you handle your emotions, reactions, and stress without compromising professional performance? At least we now acknowledge that new doctors are human and have vulnerabilities. Not doing so was still acceptable in the '80s.

The Twitter hashtags \#newdocsday and \#tipsfornewdocs provide a wealth of useful information. I wish luck to all new starters this month. I hope to be as supportive as I can to those working with me-and to be told if that's not enough.

Competing interests: I have read and understood the BMJ policy on declaration of interests and have no relevant interests to declare.

Tell us about your first weeks and year as a doctor by sending a rapid response to this column. We republish the most interesting and useful as formal letters to the editor.

Provenance and peer review: Commissioned; not externally peer reviewed.

Cite this as: BMJ 2015;351:h4510

๑ BMJ Publishing Group Ltd 2015 